\title{
Evaluation of In Vitro Ovicidal Activity of Ethanolic Extracts of Prosopis juliflora (Sw.) DC (Fabaceae)
}

\author{
Rechab Sylvester Odhiambo. ${ }^{1 *}$, Kareru G. Patrick ${ }^{1}$, Kutima L. Helen ${ }^{2}$, Nyagah \\ C. Gathu ${ }^{1}$, Njonge K. Francis ${ }^{3}$, Waithaka W. Richard ${ }^{1}$, \\ ${ }^{I}$ Chemistry Department, Jomo Kenyatta University of Agriculture and Technology (JKUAT), P.O Box 62000- \\ 00200, Nairobi, Kenya \\ ${ }^{2}$ Zoology Department, JKUAT, P.O Box 62000, Nairobi, Kenya \\ ${ }^{3}$ Land Resource, Planning \& Management Department, JKUAT, P.O Box 62000-00200, Nairobi, Kenya
}

\begin{abstract}
Gastrointestinal nematode infections in ruminants have direct effects such as mortality, weaknesses, feeding efficiency and decreased productivity. Animal deaths due to nematode infections are common in tropical regions where control programs based solely on the use of synthetic anthelmintics are no longer sustainable due to increased prevalence of gastrointestinal nematode resistance, slow development of new anthelmintics, high costs to poor farmers and concerns regarding residue in food and the environment. Alternative methods of control are thus required. Prosopis juliflora is a fast-growing, drought-resistant tree adapted to poor and saline soils in arid and semi-arid lands of Kenya, inhabited by nomadic pastoralists. Analysis of the EHA data using ttest revealed that there was no statistically significant difference in the activities of both LEE and REE $(p>0.05)$. However, in comparison to $A L B$, the difference in activity was significantly different $(p<0.05)$. The observed in vitro anthelmintic activity was attributed to saponins and condensed tannins and to alkaloids present in the plant. Phytochemical analysis confirmed presence of tannins, saponins and alkaloids, among other phytoconstituents. These phytochemicals are known to exhibit anthelmintic activity, therefore making the plant a potential candidate for drug development against gastrointestinal nematodes.
\end{abstract}

Keywords: Anthelmintic, ovicidal, Ruminants, saponins, Tannins

\section{Introduction}

The economic impact of parasitic gastroenteritis caused by mixed infection with gastrointestinal nematodes (GIN), as a production disease in ruminants lies in direct losses involving mortality due to the clinical form of the disease and also indirect losses due to weaknesses, loss of appetite, decreased feed efficiency, reduced weight gain and decreased productivity. In Kenya, economic loss to the agricultural sector due to parasitic helminth infections of small ruminants is enormous [1] and control programs based on the use of synthetic anthelmintics are no longer sustainable due to high prevalence of gastrointestinal nematode resistance, slow development of new anthelmintics, high costs to poor farmers and concerns regarding residue in food and the environment [2]. Alternative methods of control such as use of tanniferous plants are thus required for introduction into farm production systems [3]. Prosopis juliflora (Sw.) DC (Fabaceae) is an evergreen tree native to South America, Central America and the Caribbean. Prosopis species are generally fast-growing, drought-resistant, nitrogen-fixing trees or shrubs adapted to poor and saline soils in arid and semi-arid zones [4].

\section{Materials and Methods}

General Experimental Procedures

All the analytical grade solvents and reagents used for this research were from Aldrich Chemical Company Ltd., England and Merck, Germany, acquired from Kobian Kenya while a commercial anthelmintic drug, Valbazene (2.5\% Albendazole, Ultravertis E.A) was purchased from an agro-veterinary shop at Juja, Kenya.

\subsection{Sample collection, preparation and extraction}

Leaves and root bark samples of P. juliflora, obtained from Endao, Marigat District, in Baringo County of Kenya were botanically identified and authenticated by a field officer from Kenya Forestry Research Institute, Marigat station and a taxonomist from Botany Department of Jomo Kenyatta University of Agriculture and Technology, where voucher specimens were also deposited. The collected materials were washed thoroughly in water, chopped; air dried for two week, pulverized in electric grinder and exhaustively extracted using $80 \%$ ethanol. The extracts were concentrated in vacuo, dried and stored at $4^{\circ} \mathrm{C}$ until required for bioassay. 


\subsection{Phytochemical Screening}

Phytochemical screening was performed using standard phytochemical procedures [5] and the extracts were tested for flavonoids, saponins, tannins, alkaloids, triterpenes and sterols.

\subsubsection{Test for flavonoids}

Two methods were used to test for flavonoids. First, dilute ammonia $(5 \mathrm{ml})$ was added to a portion of an ethanolic extract. Concentrated sulphuric acid $(1 \mathrm{ml})$ was then added. A yellow colouration that disappeared on standing indicated the presence of flavonoids. Second, a portion of the extract was heated with $10 \mathrm{ml}$ of ethyl acetate over a steam bath for $3 \mathrm{~min}$. The mixture was thereafter filtered and $4 \mathrm{ml}$ of the filtrate shaken with $1 \mathrm{ml}$ of dilute ammonia solution. A yellow colouration indicated the presence of flavonoids.

\subsubsection{Test for saponins}

The ethanolic extracts were diluted with $20 \mathrm{ml}$ of distilled water and then agitated in graduated cylinders for 15 minutes. The formation of $1 \mathrm{~cm}$ layer of foam showed the presence of saponins. The frothing was mixed with 3 drops of olive oil and shaken vigorously after which it was observed for the formation of an emulsion.

\subsubsection{Test for tannins}

About $0.5 \mathrm{~g}$ of each extract was boiled in $10 \mathrm{ml}$ of water in a test tube and then filtered. A few drops of $0.1 \%$ ferric chloride was added to the filtrate and observed for brownish green or a blue-black colouration.

\subsubsection{Test for alkaloids}

Half a gram $(0.5 \mathrm{~g})$ of ethanolic extract was stirred with $5 \mathrm{ml}$ of $1 \% \mathrm{HCl}$ on a steam bath. The solution obtained was then filtered and $1 \mathrm{ml}$ of the filtrate treated with two drops of Mayer's reagent. Turbidity of the extract filtrate on addition of Mayer's reagent was regarded as evidence for the presence of alkaloids in the extract.

\subsubsection{Test for sterols and triterpenes}

Ten millilitres $(10 \mathrm{ml})$ of each ethanolic extract was placed in a small beaker $(50 \mathrm{ml})$ and evaporated to dryness. The residue was treated with $0.5 \mathrm{ml}$ of acetic anhydride and $0.5 \mathrm{ml}$ of chloroform. The solution was transferred into a dry test tube and concentrated solution of sulphuric acid $(2 \mathrm{ml})$ added slowly. Brownish red or violet rings at the zone of the contact with the supernatant and green or violet coloration denoted the presence of sterols and triterpenes.

\subsection{Egg Hatch Assay (EHA)}

\subsubsection{Recovery of Helminthes Eggs}

Mixed GIN eggs were recovered from sheet droppings. Sample of sheep droppings (10-15 g) were collected from sheep infected with mixed GIN. The faecal samples were suspended in water and cleared of organic debris by filtration through $1 \mathrm{~mm}$ and $150 \mu \mathrm{m}$ sieves. Eggs were collected on a $25 \mu \mathrm{m}$ sieve and further cleared of organic debris by centrifugation in magnesium sulphate (density 1.10) for five minutes at $1000 \times \mathrm{g}$. The supernatant was filtered through $100 \mu \mathrm{m}$ and $63 \mu \mathrm{m}$ sieves and the eggs were washed in water and collected on a $25 \mu \mathrm{m}$ sieve. The concentration of eggs was estimated in $200 \mu \mathrm{L}$ samples and adjusted to $500 \mathrm{eggs} / \mathrm{mL}$. 5 $\mu \mathrm{g} / \mathrm{mL}$ amphotericin B solution (Sigma, Germany) was added to the egg suspension to avoid fungal development [6]. Identification of the mixed GIN using morphological characteristics [7, 8] showed that the main species were Haemonchus contortus, Trichostrongylus spp. and Oesophagostomum spp. with an estimated prevalence rate of $60 \%, 25 \%$ and $15 \%$ respectively.

\subsubsection{In vitro ovicidal activity}

The egg hatch assay (EHA) was carried out using the World Association for the Advancement of Veterinary Parasitology (W.A.A.V.P.) guidelines for determination of anthelmintic resistance[9] with modifications that allowed the testing of the natural compounds[10]. Egg suspension of 100 $\mu 1$ containing approximately 50 fresh eggs was distributed in a 48-well flat-bottomed microtitre plate and mixed with the same volume of plant extracts dissolved in PBS having different concentrations ranging from 0.03125 to $2 \mathrm{mgmL}^{-1}$. Albendazole dissolved in $0.3 \%$ dimethyl sulfoxide (DMSO) and diluted at concentrations between 0.03125 and $2 \mathrm{mgmL}^{-1}$ was used as a positive control while negative control plates contained the diluent (PBS or $0.3 \%$ DMSO) and the egg solution. The eggs were incubated in this mixture for $48 \mathrm{~h}$ at $27^{\circ} \mathrm{C}$ and $70 \%$ relative humidity. After this time a drop of Lugol's iodine solution was added to stop the eggs from hatching. The number of eggs which had not hatched and number of hatched larvae were counted and percentage hatching calculated. There were three replicates for each concentration and control. 


\subsection{Extraction yield}

\section{Results and Discussion}

Ethanolic extraction of the roots gave a higher yield of $16.78 \%$ as compared to that of the leaves which was $6.94 \%$, an indication that there were more polar compounds in roots as compared to the leaves.

\subsection{Phytochemical profile of ethanolic extracts}

Results for Phytochemical analysis as shown in table 1 revealed that leaf ethanolic extract (LEE) and root ethanolic extract (REE) possess alkaloids, tannins, saponins, flavonoids, sterols and triterpenes. These phytochemical principles could be responsible for its observed pharmacological activity.

Table 1: Phytochemical profile of LEE and REE of $P$. juliflora

\begin{tabular}{lcc}
\hline Secondary metabolite & LEE & REE \\
\hline Alkaloids & + & + \\
Tannins & + & + \\
Saponins & + & ++ \\
Flavonoids & + & + \\
Sterols/ Triterpenes & + & + \\
\hline
\end{tabular}

'+ ' Present, ‘++ ' Present in high concentration, LEE: Leaf Ethanolic extract; REE: Root Ethanolic Extract

\subsection{Egg Hatch Assay (EHA)}

In the search for natural anthelmintics, in vitro tests are used as preliminary studies of plants. In these tests, the plant extracts are directly placed in contact with the eggs, larvae or adult parasites to evaluate the effect on egg hatching, larval development or motility and mortality of adult worms [11]. Analysis of the EHA data using t-test revealed that there was no statistically significant difference in the activities of both LEE and REE $(p>0.05)$. However, in comparison to ALB, the difference in activity was significantly different $(p<0.05)$. ALB concentrations of 0.25 to $2 \mathrm{mgmL}^{-1}$ exhibited complete inhibition on egg hatching as shown in figure 1 . Complete inhibition on egg hatching was also exhibited by LEE at the highest concentration of $2 \mathrm{mgmL}^{-1}$. The $\mathrm{ED}_{50}$ values for the extracts and albendazole are as shown in table 2.

Table 2: Effective Dose $\left(\mathbf{E D}_{50}\right)$ values for $\mathrm{EHA}$

\begin{tabular}{cccc}
\hline \multirow{2}{*}{ Extract } & \multicolumn{3}{c}{$\mathbf{9 5 \%}$ Confidence Limits for CONCENTRATION } \\
\cline { 2 - 4 } & ED $_{\mathbf{5 0}}$ value $\left(\mathbf{m g m L}^{-\mathbf{1}}\right)$ & Lower Boundary & Upper Boundary \\
\cline { 2 - 4 } ALB & 0.023 & 0.013 & 0.038 \\
LEE & 0.307 & 0.216 & 0.443 \\
REE & 0.364 & 0.256 & 0.525 \\
\hline
\end{tabular}

The observed inhibitory effect on helminthes egg hatching was due to various principles present in $P$. juliflora extracts and this observation is consistent with other research findings that plant phytochemicals such as resins, bitter principles, tannins, flavonoids and indolquinolizidine alkaloids exhibit high anthelmintic activity against strongyle nematodes of small ruminant animals by preventing parasite eggs from hatching [12].

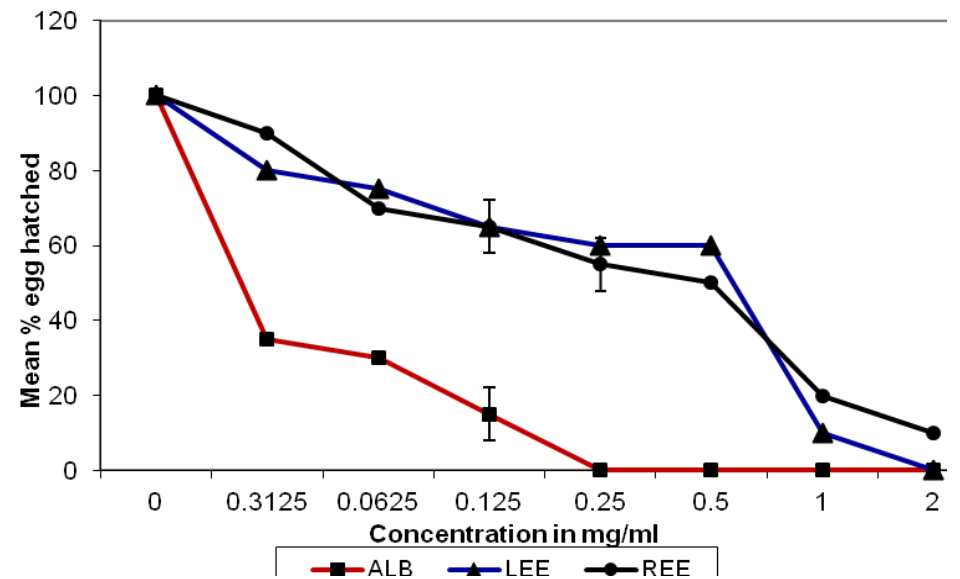

Figure1: Graph showing mean percentage egg hatching of various concentrations of LEE, REE and ALB after 48 hours 
The anthelmintic activity of LEE and REE may be attributed to presence of phytochemicals such as saponins, tannins and alkaloids. Condensed tannins might diffuse through the external surfaces such as eggshells and bind to egg proteins thus inhibiting egg hatching and larval development [13]. Saponins destabilize membranes and increase cell permeability by combining with membrane-associated sterols[14]. Other phytochemicals like flavonoids and oleane type triterpenes may also have their independent or synergistic effects [15]. The use of botanical anthelmintics has been proposed as an alternative strategy for the control of gastrointestinal nematode infections in order to reduce the dependence on chemical anthelmintic treatments and to delay the selection and the transmission of anthelmintic resistances in worm populations [16].

\section{Conclusion}

In the present study, we found that most of the biologically active phytochemicals were present in the ethanolic extracts of Prosopis juliflora and its medicinal properties could be due to the presence of these phytochemicals acting either independently or synergistically. This study, therefore, has provided biochemical basis for the use of extracts from P. juliflora in the treatment and prevention of helminth infections. However, further studies are recommended to isolate and elucidate the active components responsible for the observed activity.

\section{Acknowledgement} project.

The authors acknowledge Jomo Kenyatta University of Agriculture and Technology for funding the

\section{References}

[1] J. B. Githiori. Evaluation of anthelmintic properties of ethnoveterinary plants preparations used as livestock dewormers by pastoralist and small holder farmer in Kenya. Doctoral dissertation, Department of Biomedical Sciences and Veterinary Public Health, SLU. Acta Universitatis Agricultural sulciae, p. 76, 2004.

[2] Singh, D.; Swarnkar, C. P.; Khan, F. A. Anthelmintic resistance in gastrointestinal nematodes in livestock in India. Journal of Veterinary Parasitology, 16: 115-130, 2002.

[3] Niezen, J. H.; Charleston, W. A. G.; Robertson, H. A.; Shelton, D.; Whaghorn, G. C.; Green, R. The effect of feeding sulla (Hedysarum coronarium) or lucerne (Medicago sativa) on lamb parasite burdens and development of immunity to gastrointestinal nematodes. Veterinary Parasitology, 105: 229-245, 2002.

[4] Pasiecznik, N.; Peter Felker, P. J. C.; Harris, L. N.; Harsh, G.; Cruz, J. C.; Tewari, K.; Maldonado, L. J. The Prosopis julifloraProsopis pallida complex: A monograph. HDRA, Coventy, UK, 2001.

[5] Harborne, J. B. Phytochemical Methods: A guide to Modern Techniques of Plant Analysis. 3rd edition. Chapman and Hall Ltd, London, pp 279, 1998.

[6] Hubert, J.; Kerbouef, D. A. microlarval development assay for the detection of anthelmintic resistance in sheep nematodes. Veterinary Record, 130: 442-446, 1992.

[7] Hansen, J.; Perry, B. The Epidemiology, Diagnosis and Control of Helminth Parasites of Ruminants. (Handbook), International Laboratory for Research on Animal Diseases Press, Nairobi, Kenya, 1994. Electronic version available in www.fao.org/wairdocs/ILRI/x5492E/x5492E00.HTM

[8] Van Wyk, J. A.; Cabaret, J.; Michael, L. M. Morphological identification of nematode larvae of small ruminants and cattle simplified. Veterinary Parasitology, 119: 277-306, 2004.

[9] Coles, G. C.; Bauer, C.; Borgsteede, F. H.; Geerts, S.; Klei, T. R.; Taylor, M. A.; Waller, P. J. World Association for the Advancement of Veterinary Parasitology (W.A.A.V.P.) methods for the detection of anthelmintic resistance in nematodes of veterinary importance. Veterinary Parasitology, 44: 35-44, 1992.

[10] Alawa, C. B. F.; Adamu, A. M.; Gefu, J. O.; Ajanusi, O. J.; Abdou, P. A.; Chiezey, N. P.; Alawa, J. N.; Bowman, D. D. In vitro screening of two medicinal plants (Vernonia amygdalina and Annona senegalensis) for anthelmintic activity. Veterinary Parasitology, 1 (13): 73-81, 2003.

[11] Hammond, J. A.; Fielding, D.; Bishop, S. C. Prospects for plant anthelmintics in tropical veterinary medicine. Veterinary Research Communication, 21: 213-228, 1997.

[12] Onyeyili, P. A.; Nwosu, C. O.; Amin, J. D; Jibike, G. I. Anthelmintic activity of crude aqueous extract of Nauclea latifolia stem bark against ovine nematodes. Fitoterapia, 72: 12-21, 2001.

[13] Min, B. R.; Barry, T. N.; Attwood, G. T.; McNabb, W. C. The effect of condensed tannins on the nutrition and health of ruminants fed fresh temperate forages: a review. Animal Feed Science and Technology, 106: 3-19, 2003.

[14] Gee, J. M.; Johnson, I. T. Interaction between haemolytic saponins, bile salts and small intestinal mucosa in rat. Journal of Nutrition, 118: 1391-1397, 1988

[15] A. Brantner, Z. Males, S. Pepeljak, A. Antolic, Antibacterial activity of Paliurus spina-christi Mill (Christ's thorn), Journal of Ethnopharmacology, 52, 1996, 119-122.

[16] H. Hoste, F. Jackson, S. Athanasiadou, S.M. Thamsborg, S.O. Hoskin, The effects of tannin-rich plants on parasitic nematodes in ruminants, Trends Parasitology, 22, 2006, 253-261. 